\title{
Self-medication practice among Yemeni patients in Ibb city: a survey study exploring patients' perceptives
}

\author{
Salah Mogali ${ }^{1}$, Saad Al-Ghanim ${ }^{1}$, Ahmed Mohammed Saleh Alduais ${ }^{* 2}$, Bader F. Al-Shabrani ${ }^{1}$ \\ ${ }^{1}$ Department of Health Administration, College of Business Administration, King Saud University, Riyadh, Kingdom of Saudi \\ Arabia \\ ${ }^{2}$ Clinical Linguistics Stream, Department of Linguistics, Institute of Social Sciences, Ankara University, Sihhiye, Ankara, Turkey
}

Received: December 28, 2014

DOI: $10.5430 /$ jha.v4n4p32
Accepted: April 15, $2015 \quad$ Online Published: May 8, 2015

URL: http://dx.doi.org/10.5430/jha.v4n4p32

\begin{abstract}
Background: The main objective of this study was addressing the prevalence of self-medication, its causes, sources of information and medications in Ibb city, the Republic of Yemen.

Methods: This study followed a survey-study method where the data was collected using a self-administrated questionnaire with stratified random sampling and simple random sampling procedures to select the study samples. A sample of 500 patients from the three major hospitals at Ibb city (AL-Thawrah, Nasser and Motherhood hospitals) were selected in this study. Both descriptive and referential analyses were used to answer the raised research questions.

Results: The results indicated that $85 \%$ of the participants practiced self-medication in the last three months prior to data collection. The most reason reported for self-medication is that the drug supply in hospitals was unavailable. The most source of information about self-medication reported by respondents was pharmacists and the most source of medication was private pharmacies. Besides, more than half of the participants indicated prior knowledge regarding the dangers of self-medication. Chi-square analysis indicated that respondents who are urban, married and older than 40 years are more likely to practice self-medication.

Conclusions: Educational campaigns and strict legislation measures relating to drugs dispensing from private pharmacies, supplying the governmental hospitals with the medications and facilitate access to health care services are among the necessary intervention(s) that may modify the behavior of individuals and protect them from potential dangers of self-medication.
\end{abstract}

Key Words: Self-medication, Yemen's public health, Private sector pharmacies, Public health awareness

\section{INTRODUCTION}

Self-medication might certainly albeit gradually lead to selfkilling. According to the world health organization the Selfmedication is defined as "selection and use of medicines by individuals (or a member of the individuals' family) to treat self-recognized or self-diagnosed conditions or symptoms". In general, the self-medication has benefits when it is used properly and has risks when it is used improperly. ${ }^{[1-3]}$
Among the benefits of the self-medication are the easy access to drugs when some people do not have time to meet the doctors and wait in hospitals for long time; they just need a rapid relief of pain. In addition, the self-medication also may be effective in treatment of some diseases such as storks. ${ }^{[4]}$ However the safety is not guaranteed in all cases and all times.

*Correspondence: Ahmed Mohammed Saleh Alduais; Email: amsalduais@gmail.com; Address: Clinical Linguistics Stream, Department of Linguistics, Institute of Social Sciences, Ankara University, 06100, Sihhiye, Ankara, Turkey. 
There are many dangers of self-medication as reported in some studies such as the incorrect self-diagnosis of diseases or health problems, incorrect dose of drugs, incorrect duration and the frequency. Some of those drugs may result in addiction. Moreover, some of them can react adversely with other drugs which result in a dangerous effect. Other drugs may result in body resistance for diseases; this case mostly occurs with the antibiotics (antimicrobial). This is common in developing countries. ${ }^{[5-7]}$ Therefore, we cannot consider the self-medication as a harmful or useful but fully dependent. ${ }^{[8]}$ Some drugs are also available in some developed countries in general grocery stores and private pharmacies and can be taken without any prescriptions called over the counter (OTC). There are many sources of self-medication either from the private pharmacies (chemical drugs) or from the herbal sources (herbs drugs) or spiritual (Rohani). The selection from these sources depends on people's culture, beliefs and economy. All of these factors differ from country to another.

The prevalence of self-medication in different countries ranges from low percentage in Ethiopia 26.2\%, Mexico $34 \%$, Bambui 54\%, ${ }^{[6]}$ Palestine $(56.0 \%),{ }^{[5]}$ Nepal 59\%, ${ }^{[6]}$ to high percentage in Indonesia $60 \%,{ }^{[9]} 61.2 \%$ in Pakistan, ${ }^{[1]}$ Malaysia 62.7\%, ${ }^{[10]}$ Honk Kong, ${ }^{[11]}$ China 63.1\%, Brazil $86.4 \%,{ }^{[12]}$ UAE $89.2 \%{ }^{[13]}$ and finally in Slovenia $94.9 \% . .^{[14]}$

Self medication has many causes. In other words, different studies reported the reasons of self-medication. For example, the study in Pakistan confirmed that the most common reasons of self-medication practice were lack of time (37\%) and economic issues $(33 \%){ }^{[8]}$

A similar study in Pakistan ${ }^{[1]}$ reported that the mild illness (41.8\%) was determined as the most common reason. Generally higher proportion of participants reported "previous experience" and "time saving" as the most common reasons for the practice of self-medication in contrast to "economical" and "lack of health care facilities" described by rural participants. The mild illness and the previous experience also were reported by other researchers. ${ }^{[2,5,15-17]}$ However, the study in Malaysia reported that the most common cause for the self-medication is that the effectiveness of OTC drugs. ${ }^{[10]}$ In his study, $62.7 \%$ of participants believed that OTC medicines were effective like those prescribed by physicians.

Most of the previous studies related the most common diseases to OTC drugs used in self-medication. The study reported that the fever $(31 \%)$, headache $(19 \%)$, and abdominal pain $(16.7 \%)$ were the most common illnesses resulted from the use of self-medication drugs. ${ }^{[18]}$ Other common diseases such as cold, cough, headache, pain and fever were treated by the (Paracetamol) drugs. ${ }^{[1,2,8,13,16]}$ On the other hand, treating cold and respiratory problems is through using the most common antibiotic drug (Amaxicillin). ${ }^{[6,17,19]}$

The most common source of the information was from pharmacists as has been reported by. ${ }^{[13,15,18]}$ Self-decision was also considered as one of the most sources of medication information. ${ }^{[1,15,16]}$ The studies illustrated that the most common sources of information were pharmacies and other health care providers. ${ }^{[2,10]}$ Nevertheless, another study stated that the most common source of the information were friends and patients' previous prescriptions. ${ }^{[20]}$

Most of the previous studies didn't evaluate the knowledge of participants regarding the risks of the self-medication, but the study reported that $66 \%$ of participants believed that self-medications is harmless. ${ }^{[18]}$ Other studies in other countries evaluated self-medication in terms of the causes and the types of drugs mostly used, but the researcher in this study added some variables like the source of medication (drugs). Moreover, the researcher in this study assessed the risks of self-medication (awareness of patients regarding the risk of self-medication). In our society, no previous studies indicated the percentage of the self-medication in Yemen. There is a previous study which has been done in the city of hajjah, Yemen in self-medication but was confined to the treatment of people with the anti-malarial drugs only. ${ }^{\text {[21] }}$

To conclude, the problem of self-medication is widely spread in developing countries; Yemen is not exceptional. In Yemen, the quality of healthcare services isn't in a good condition and it needs great efforts to be developed. The phenomenon of self-medication is widely spread in the Republic of Yemen. ${ }^{[22,23]}$ The private sector's pharmacies are the most accessible health facilities and people can obtain most types of medication without prescription making the selfmedication easy to be practiced. A previous study was conducted in Yemen about the antibiotics self-medication among the children and showed highly alarming percentage representing $60 \%$. $^{[23]}$

Thus, the main aim of the current study was to explore the prevalence of self-medication among the Yemeni patients in Ibb governorate in addition to exploring the causes behind this phenomenon. Since there was no previous study in such field, it's difficult to treat the problem without describing the situation first. The below raised questions were accounted for:

(1) How many of the included population took drugs without prescriptions (prevalence of self-medication) during the last three months?

(2) Why do some patients tend to medicate themselves instead of seeking medication by a physician (reasons for self-medication)? 
(3) What are the information sources for patients for purchasing and using drugs without a prescription?

(4) What are the sources of medication (drugs)?

(5) Are the patients aware about the dangers of selfmedication?

\section{METHOD AND MATERIAL}

\subsection{Research design}

The researcher followed a survey-study method. In other words, this explorative descriptive study was conducted in Ibb city, Yemen to assess self-medication.

\subsection{Population and sampling}

\subsubsection{Population}

The study population consisted of all patients who came to the three main governmental hospitals (Al-Thawrah , Nasser, Motherhood) at Ibb city during the time of conducting the research project. In other words, during the identified period of the study conduction, nurses from the three hospitals were informed and provided with the survey to fill in with every coming patient.

\subsubsection{Sampling procedure}

The sample consisted of 384 patients and later on increased into 500 patients for more valid and reliable data. The stratified sampling method was used to to select three hospitals at Ibb city, Yemen. That is to say, this selection was based on the basis of which hospitals in this city receive more patients and the major ones the three selected hospitals in this study. Then the simple random sampling method was used to select the patients. Age responses were coded in four groups. During the analysis 20 - 30 years and 31 - 40 compiled under one group $(\leq 40)$. The same process with the $41-50$ and 50 and above under one group ( $>40$ ), was used.

\subsection{Instruments}

The instrument used in this study was a questionnaire which was developed by the researchers for the purpose of this study. The questionnaire was originally designed in Arabic Language (the native language in the Republic of Yemen). Likert scale, nominal scale and yes and no questions were used in this questionnaire. It (the questionnaire) consisted of 6 sections:

(1) Section 1: demographic information (age, sex, education level, employment status, marital status, chronic diseases and general health status);

(2) Section 2: prevalence of using self-medications;

(3) Section 3: reasons for self-medication (likert five scale);
(4) Section 4: information sources of self-medication (Nominal scale);

(5) Section 5: sources of medications (Nominal scale);

(6) Section 6: awareness of self-medications side effects (Yes No scale).

Table 1. Evaluation scale

\begin{tabular}{ll}
\hline Weighted mean & Level \\
\hline from 1.00 to 1.79 & strongly disagree \\
from 1.80 to 2.59 & disagree \\
from 2.60 to 3.39 & neutral \\
from 3.40 to 4.19 & agree \\
from 4.25 to 5.00 & strongly agree \\
\hline
\end{tabular}

\subsection{Validity and reliability}

To assure the validity, the following procedures were followed. Firstly, reviewing the literature and previous instruments were examined to develop drafts. Secondly, the questionnaire was given to professors of health care administrator for evaluation. Finally, a pilot survey upon 50 adult Yemeni students (50 male) was conducted in King Saud University in Riyadh city. It should be noted; however, since the purpose was just to validate the tool and environment was not an influencing variable so the pilot study was conducted in Saudi Arabia instead of Yemen. On the basis of the suggestions of the reviewers and the outcome of the pilot study, a few questions were reformulated and others were added or deleted in the main study. The pilot survey questionnaires were not included in the main survey. Reliability was measured by using Cronbach's alpha tool which indicated (.70).

\subsection{Data-collection}

The researchers gathered data through (volunteers). The researchers explained the tools used in the study before collecting sample data. After that, the forms were distributed directly to the patients. The forms were filled out in the presence of one of the researchers in case of some participants might need assistance. An average of 5 minutes was required to complete the instrument. Total of (500) forms were distributed. Four hundred ninety (490) forms were returned. Two forms were not completed. The response rate was $97.6 \%$.

\subsection{Data-analysis}

The data gathered was evaluated and went through statistical analysis. The $20^{\text {th }}$ version of SPSS (Statistical Package for Social Sciences) was used to run the analysis of the collected data. 


\section{RESUltS}

With reference to the objectives of this study, the following questions were raised:

(1) How many of the included population took drugs without prescriptions (prevalence of self-medication) during the last three months?

(2) Why do some patients tend to medicate themselves instead of seeking medication by a physician (reasons for self-medication)?

(3) What are the information sources for patients for purchasing and using drugs without a prescription?

(4) What are the sources of medication (drugs)?

(5) Are the patients aware about the dangers of selfmedication?

Table 2. Socio-demographic characteristics of participants

\begin{tabular}{|c|c|c|c|}
\hline & Variables level & Frequency & $\%$ \\
\hline \multirow{3}{*}{ Gender } & Male & 231 & 47.3 \\
\hline & Female & 257 & 52.7 \\
\hline & Total & 488 & 100 \\
\hline \multirow{5}{*}{ Age } & $20-30 y$ & 113 & 23.2 \\
\hline & $31-40 y$ & 96 & 19.7 \\
\hline & $41-50 y$ & 117 & 24.0 \\
\hline & 51-above & 162 & 33.2 \\
\hline & Total & 488 & 100 \\
\hline \multirow{3}{*}{ Place of residence } & Urban & 344 & 70.5 \\
\hline & Rural & 144 & 29.5 \\
\hline & Total & 488 & 100 \\
\hline \multirow{3}{*}{ Marital status } & Single & 149 & 30.5 \\
\hline & Married & 339 & 69.5 \\
\hline & Total & 488 & 100 \\
\hline \multirow{3}{*}{ Employment status } & Employed & 210 & 43.0 \\
\hline & Unemployed & 278 & 57.0 \\
\hline & Total & 488 & 100 \\
\hline \multirow{6}{*}{ Level of education } & High school, less & 167 & 34.2 \\
\hline & Diploma & 69 & 14.1 \\
\hline & Bachelors & 108 & 22.1 \\
\hline & Higher education & 49 & 10.0 \\
\hline & Without certificate & 95 & 19.5 \\
\hline & Total & 488 & 100 \\
\hline \multirow{3}{*}{$\begin{array}{l}\text { Q1: Do you suffer } \\
\text { from any chronic } \\
\text { disease? }\end{array}$} & Yes & 135 & 27.7 \\
\hline & No & 353 & 72.3 \\
\hline & Total & 488 & 100 \\
\hline \multirow{3}{*}{$\begin{array}{l}\text { Q2: What is your } \\
\text { assessment of your } \\
\text { health in general? }\end{array}$} & Good & 368 & 75.4 \\
\hline & Bad & 120 & 24.6 \\
\hline & Total & 488 & 100 \\
\hline
\end{tabular}

It can be seen that nearly more than the half of participants were females representing $52.7 \%$. It can be also noticed that most of the participants under age range 51 years and above representing 33.2\% and from urban areas representing $70.5 \%$ and the majority of participants were married representing $(69.5 \%)$. In regard to employment status, more than half of participants are unemployed representing 57\%. The general evaluation of the health of participants as reported was good representing $75.4 \%$ (see Table 2).

Table 3. Self-prescription medicine taking

\begin{tabular}{lll}
\hline Scale & Frequency & \% \\
\hline Yes & 415 & 85.0 \\
No & 73 & 15.0 \\
Total & 488 & 100.0 \\
\hline
\end{tabular}

Most of participants use the self-medication during the last three months representing (85\%) (see Table 3).

Table 4. Frequency of self-prescription medicine taking

\begin{tabular}{lll}
\hline Scale & Frequency & $\mathbf{\%}$ \\
\hline Rare & 197 & 47.5 \\
Sometime & 161 & 38.8 \\
Often & 28 & 6.7 \\
Always & 29 & 7.0 \\
Total & $415^{*}$ & 100.0 \\
\hline
\end{tabular}

${ }^{*} \mathrm{~N}=(488-73=415)$ (the persons who use the self-medication, answer this question)

Most of self-medication users (197) use medication rarely and represent $(47.5 \%)$ (see Table 4).

We can see from the above Table 5 that the participants vary in responding to the causes of self-medication with the mean range from $\mu=4.06$ to $\mu=3.41$. The highest mean range was for "drug supply in hospitals was unavailable" as compared to the lowest mean "having enough knowledge". This statistical ranking could give us an initial list for causes of treatment with the average mean $\mu=3.75$ in which the participants agree regarding the causes of self-medication.

The above Figure 1 indicates that the number one source of information as reported was the pharmacies (78.3\%) followed by the previous prescription (36.7\%), and classes as the least one $(14.1 \%)$.

With reference to the above Figure 2, the drugs purchased from the private pharmacies was the most commonly source of self-medication representing $(89.8 \%)$ and the use of leftover medicine was prevalent but in a minimum percentage representing (23\%). The least source of medication reported by the participants was the others (herbal medicine) representing only (10.9\%).

According to the above Table 6, nearly more than half of the participants have a knowledge about the dangers of the self-medications which represent $54.1 \%$. 
Table 5. Medicine taking reasons

\begin{tabular}{|c|c|c|c|c|c|c|c|c|c|}
\hline Statements & & $\begin{array}{l}\text { Strongly } \\
\text { disagree }\end{array}$ & Disagree & Neutral & Agree & $\begin{array}{l}\text { Strongly } \\
\text { agree }\end{array}$ & Total & Mean & $S D$ \\
\hline \multirow{2}{*}{$\begin{array}{l}\text { 1. Drug supply in hospitals was } \\
\text { unavailable }\end{array}$} & Frequency & 11 & 14 & 52 & 270 & 141 & 488 & \multirow{2}{*}{4.06} & \multirow{2}{*}{.843} \\
\hline & $\%$ & 2.3 & 2.9 & 10.7 & 55.3 & 28.9 & $100 \%$ & & \\
\hline \multirow{2}{*}{$\begin{array}{l}\text { 2. Availability of medicine without } \\
\text { prescription }\end{array}$} & Frequency & 15 & 29 & 48 & 227 & 169 & 488 & \multirow{2}{*}{4.04} & \multirow{2}{*}{.980} \\
\hline & $\%$ & 3.1 & 5.9 & 9.8 & 46.5 & 34.6 & $100 \%$ & & \\
\hline \multirow{2}{*}{$\begin{array}{l}\text { 3. The difficulty of accessing } \\
\text { health services }\end{array}$} & Frequency & 2 & 21 & 80 & 254 & 131 & 488 & \multirow{2}{*}{4.01} & \multirow{2}{*}{.802} \\
\hline & $\%$ & .4 & 4.3 & 16.4 & 52 & 26.8 & $100 \%$ & & \\
\hline \multirow{2}{*}{$\begin{array}{l}\text { 4. Feel no need to consult doctors } \\
\text { "mild illness" }\end{array}$} & Frequency & 15 & 28 & 39 & 280 & 126 & 488 & \multirow{2}{*}{3.97} & \multirow{2}{*}{.919} \\
\hline & $\%$ & 3.1 & 5.7 & 8.0 & 57.4 & 25.8 & $100 \%$ & & \\
\hline \multirow{2}{*}{$\begin{array}{l}\text { 5. Uses of drugs in emergency } \\
\text { cases }\end{array}$} & Frequency & 7 & 52 & 37 & 295 & 97 & 488 & \multirow{2}{*}{3.87} & \multirow{2}{*}{.902} \\
\hline & $\%$ & 1.4 & 10.7 & 7.6 & 60.5 & 19.9 & $100 \%$ & & \\
\hline \multirow{2}{*}{ 6. High costs of treatment } & Frequency & 28 & 18 & 81 & 231 & 130 & 488 & \multirow{2}{*}{3.85} & \multirow{2}{*}{1.038} \\
\hline & $\%$ & 5.7 & 3.7 & 16.6 & 47.3 & 26.6 & $100 \%$ & & \\
\hline \multirow{2}{*}{$\begin{array}{l}\text { 7. Prior knowledge that the Doctor } \\
\text { will give me the some drugs }\end{array}$} & Frequency & 14 & 24 & 94 & 244 & 112 & 488 & \multirow{2}{*}{3.85} & \multirow{2}{*}{.926} \\
\hline & $\%$ & 2.9 & 4.9 & 19.3 & 50 & 23 & $100 \%$ & & \\
\hline \multirow{2}{*}{$\begin{array}{l}\text { 8. Previous experience with disease } \\
\text { and treatment }\end{array}$} & Frequency & 11 & 61 & 94 & 229 & 93 & 488 & \multirow{2}{*}{3.68} & \multirow{2}{*}{.993} \\
\hline & $\%$ & 2.3 & 12.5 & 19.3 & 46.9 & 19.1 & $100 \%$ & & \\
\hline \multirow{2}{*}{$\begin{array}{l}\text { 9. The lack of transportation to get } \\
\text { to hospitals }\end{array}$} & Frequency & 47 & 24 & 85 & 246 & 86 & 488 & \multirow{2}{*}{3.61} & \multirow{2}{*}{1.126} \\
\hline & $\%$ & 9.6 & 4.9 & 17.4 & 50.4 & 17.6 & $100 \%$ & & \\
\hline \multirow{2}{*}{ 10. Length of therapy time } & Frequency & 78 & 24 & 59 & 218 & 109 & 488 & \multirow{2}{*}{3.52} & \multirow{2}{*}{1.326} \\
\hline & $\%$ & 16 & 4.9 & 12.1 & 44.7 & 22.3 & $100 \%$ & & \\
\hline 11 No trust in medical doctor & Frequency & 20 & 110 & 73 & 190 & 95 & 488 & 347 & 1157 \\
\hline 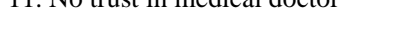 & $\%$ & 4.1 & 22.5 & 15 & 38.9 & 19.5 & $100 \%$ & $0.4 \prime$ & $1.13 /$ \\
\hline 12 Busv schedule & Frequency & 35 & 59 & 92 & 247 & 55 & 488 & 347 & 1072 \\
\hline 12. Dusy setile une & $\%$ & 7.2 & 12.1 & 18.9 & 50.6 & 11.3 & $100 \%$ & $3.4 \prime$ & $1.0 / 2$ \\
\hline 13. Have Enough knowledge & Frequency & 18 & 117 & 82 & 191 & 80 & 488 & 3.41 & 1128 \\
\hline 13. Have Ellougn kilowieage & $\%$ & 3.7 & 24 & 16.8 & 39.1 & 16.4 & $100 \%$ & 3.41 & 1.120 \\
\hline Mean average & & & & & & & & 3.75 & \\
\hline
\end{tabular}

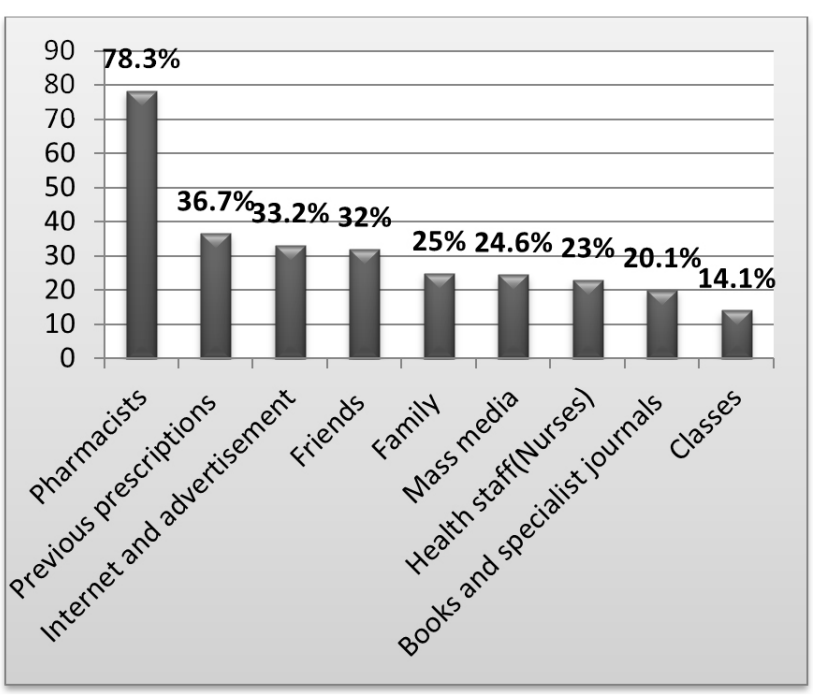

Figure 1. Self-medication information soruce

We can see from the above Table 7 that there might be a clear association between the age of the participants and the uses of the self-medications. Greater than 40 years old were more likely to practice self-medication with the $\chi^{2}=23.093$ and the $p$-value $=.000$ which is $<.05$ sig. It could be also observed that there is a possible association between the participants' residence status and the uses of self-medications. Urban participants were more likely to practice self-medication with the $\chi^{2}=5.541$ and the $p$-value $=.019$ which is $<.05$ sig.. Moreover, there might be an association between the participant's marital status and the uses of the self-medications. Married participants were more likely to practice self-medication with the $\chi^{2}=16.436$ and the $p$-value $=.000$ which is $<.05$ sig..

\section{Discussion}

Many articles have described self-medication in different nations like India, Saudi Arabia, Pakistan, China, Malaysia and Emirate (see the above stated studies in the introduction). The results of this study showed that the self-medication practices were prevalence in various age groups, gender and 
education levels. The prevalence rate of self-medication practice was $85 \%$ during the last three months (prior to data collections) which was higher than what have been reported in countries like Nepal 59\%, Bambui 54\%, Mexico 34\%, Ethiopia 26.2\%, 61.2\% Pakistan, Indonesia around 60\%, Honk Kong of China 63.1\%, Palestine 56.0\%, Malaysia $62.7 \%$, Puduchery in India $71 \%$ and finally in Uganda $75 \%$. Nevertheless, the prevalence rate in Yemen still less than that reported in some other countries like the UAE reaching $89.2 \%$, Slovenia $94.9 \%$ and Brazil $86.4 \%$.

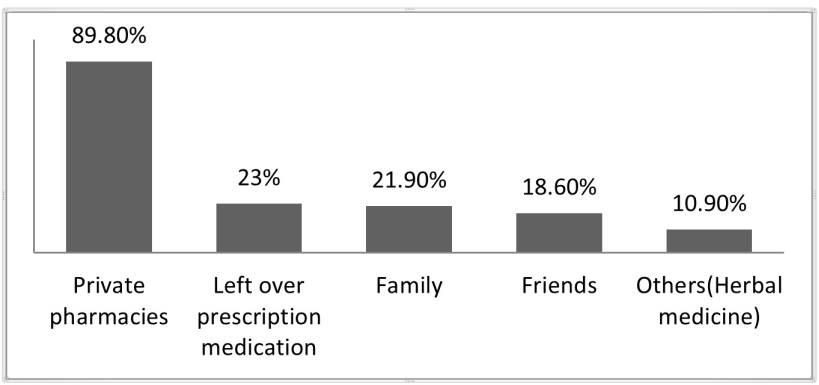

Figure 2. Medication(s) source(s)

The respondents in this study identified several reasons for the self-medication, including that "drug supply in hospitals was unavailable" $\mu=4.06$, availability of drugs without prescribing $\mu=4.04$ and the least common cause was not having enough knowledge $\mu=3.41$. The results of this study contradict with the results reported by other studies in literature. For instance, the main cause was that the "illness is minor" $80.2 \%,{ }^{[15]}$ this result is in agreement with the previously reported, ${ }^{[5,18]}$ but the knowledge about the drug and the higher cost as the causes of self-medication practice. ${ }^{[5]}$ The higher cost of treatment (economic issue) also was reported. ${ }^{[1]}$ Similarly, the researchers in this study indicated that "the difficult access to the health services" was a cause for self-medication. This result is in agreement with the result reported. ${ }^{[15]}$ The researchers also reached that the prior knowledge of patients for using the same drugs that have been prescribed by a doctor previously was another cause of practicing self-medication habit. This finding is in agreement with the findings which indicated that the medical previous experience and the loss of trust in doctor were the most common causes of self-medication practice. ${ }^{[10,22]}$

Table 6. Side effects and dangers of drugs

\begin{tabular}{lll}
\hline Scale & Frequency & \% \\
\hline Yes & 264 & 54.1 \\
No & 224 & 45.9 \\
Total & 488 & 100.0 \\
\hline
\end{tabular}

Table 7. Use of self-medication in the past three months

\begin{tabular}{|c|c|c|c|c|c|c|c|}
\hline \multirow{3}{*}{ Statements } & & \multicolumn{4}{|c|}{ Use of self-medication? } & \multirow{3}{*}{$\chi^{2}$} & \multirow{3}{*}{$p$-value } \\
\hline & & \multicolumn{2}{|c|}{ Yes } & \multicolumn{2}{|c|}{ No } & & \\
\hline & & Number & $\%$ & Number & $\%$ & & \\
\hline \multirow{2}{*}{ Sex } & Male & 193 & 83.6 & 38 & 16.5 & \multirow{2}{*}{.767} & \multirow{2}{*}{.381} \\
\hline & Female & 222 & 86.4 & 35 & 13.6 & & \\
\hline \multirow{2}{*}{ Age } & $\leq 40$ & 159 & 76.1 & 50 & 23.9 & \multirow{2}{*}{23.093} & \multirow{2}{*}{.000} \\
\hline & $>40$ & 256 & 91.8 & 23 & 8.2 & & \\
\hline \multirow{2}{*}{ Residence } & Urban & 301 & 87.5 & 43 & 12.5 & \multirow{2}{*}{5.541} & \multirow{2}{*}{.019} \\
\hline & Rural & 114 & 79.2 & 30 & 20.8 & & \\
\hline \multirow{2}{*}{ Marital status } & Single & 112 & 75.2 & 37 & 24.8 & \multirow{2}{*}{16.436} & \multirow{2}{*}{.000} \\
\hline & Married & 303 & 89.4 & 36 & 10.6 & & \\
\hline \multirow{2}{*}{ Employment } & Employee & 185 & 88.1 & 25 & 11.9 & \multirow{2}{*}{2.703} & \multirow{2}{*}{.100} \\
\hline & Unemployee & 230 & 82.7 & 48 & 17.3 & & \\
\hline \multirow{5}{*}{ Education } & High school, less & 141 & 84.4 & 26 & 15.6 & \multirow{5}{*}{6.809} & \multirow{5}{*}{.146} \\
\hline & Diploma & 53 & 76.8 & 16 & 23.2 & & \\
\hline & Bachelors & 96 & 89 & 12 & 11 & & \\
\hline & Higher education & 45 & 91.8 & 4 & 8.2 & & \\
\hline & Without certificate & 80 & 84.2 & 15 & 15.8 & & \\
\hline \multirow{2}{*}{ Chronic disease } & Yes & 115 & 85.2 & 20 & 14.8 & \multirow{2}{*}{.003} & \multirow{2}{*}{.956} \\
\hline & No & 300 & 85 & 53 & 15 & & \\
\hline \multirow{2}{*}{ Evaluation } & Good & 314 & 85.3 & 54 & 14.7 & \multirow{2}{*}{.096} & \multirow{2}{*}{.757} \\
\hline & $\mathrm{Bad}$ & 101 & 84.2 & 19 & 15.8 & & \\
\hline
\end{tabular}


More than two thirds of the participants reported that the "pharmacies" was the main source of information for selfmedication, nearly one third of the participants explained that they depend on the previous prescriptions in self-medications. This result is in agreement with the previous results reported which confirmed that pharmacies and previous prescriptions are the main sources of information. ${ }^{[2,5,13,15,18]}$

Regarding the family members and friends as the main source of medical information, the findings of this research contradict with the previous studies considering them as a main source of medical information. ${ }^{[1,8,16,24]}$

Furthermore, the findings of this research indicate that $89.9 \%$ of the participants believe that private pharmacies are the main source for getting drugs (medications) followed by the left over prescription medication (23\%) are in agreement with the previous studies. ${ }^{[8,15,20]}$

Additionally, the study indicates that the majority of selfmedication users have knowledge about the dangers of the self-medications representing (54.1\%). This result is in agreement with the studies which result in a high rate of prior knowledge of the dangers of self-medication $(66.6 \%) .{ }^{[18,19]}$

Lastly, the data of this study indicated that there might be an association between the socio-demographic data (age, residence and marital status of the participants) and the practice of self-medication. These significant possible associations illustrate that the urban, married, and older than 40 years were more likely to practice self-medication. Since most participants were from the urban areas in the study, there are no differences regarding the sex because in the urban areas both male and female can get the drugs from the pharmacies or from the other sources. The results of this study is in agreement with the result indicating the equality distributed by the gender (there were no association regarding the gender and use of self-medication). ${ }^{[8]}$ In the same sense, such a finding is also in agreement with the previous studies regarding the existence of possible significant association between the age of participants and practice of self-medication. ${ }^{[15,16,20,24]}$

\section{Conclusions}

The problem of self-medication is widely spread in developing countries; Yemen is not exceptional. In Yemen, the quality of healthcare services isn't in a good condition and it needs great efforts to be developed. The private sector pharmacies are the most accessible health facilities and people can obtain most types of medication without prescription making the self-medication easy to be practiced. Having that said, the main aim of this study was to explore the prevalence of self-medication among Yemeni patients in Ibb city along with exploring the causes behind this phenomenon.
The topic was selected with a great purpose of raising awareness about the negative effects of self-medication practice. A survey-study approach was followed where a self-made questionnaire was used for date collection from 500 participants in the three major hospitals in Ibb governorate, the Republic of Yemen. The study was concluded with that self-medication practice has been common among people in Yemen. There has been a high rate of using drugs without prescription (85\%), the urban, married, older than 40 years were the most common group of age that practice the self-medication. The most important reason that lead to selfmedication practice was the drug supply in hospitals was unavailable, believing in pharmacists as dependable information source, and the people unawareness regarding the danger of self-medication.

\subsection{Recommendations}

Based on the findings of the study, the following recommendations were made:

\section{To health agencies:}

(1) Close proper supervision is required toward the types and quality of drugs in the market and the private pharmacies;

(2) The ministry of health has to ensure that all drugs are available in all governmental hospitals and all the patients have access to health care services;

(3) To instruct all drug dispensers that all drugs should not be distributed without medical prescription, except the limited safe drug and drugs used for short period of time;

(4) The ministry of health must regulate the medical treatment cost in the governmental and private health sectors;

(5) Introduce the health insurance;

(6) Use public mass media \& public meetings for educational intervention to discuss the proper ways of drug use $\&$ possible risks and side effects of drugs;

(7) Medication advertisements in newspapers and magazines must be supervised and regulated.

\section{To pharmacists and health personnel's:}

(1) Good clarification to the patients about the drugs (duration of use \& route of administration \& side effects);

(2) Avoidance of illogical use of drugs;

(3) Advising the patients for regular checkup especially those with chronic diseases.

\subsection{Limitations}

The following limitations were observed in the current study:

(1) It was conducted in just three hospitals; 
(2) The questionnaire used is not the best data collection tool yet was the only tool used in this study;

(3) Further study should include the pharmacists' role in self-medication in which they give the drugs without prescription;

(4) The Time limitation and the unavailability of fund to conduct such type of research.

\section{REFERENCES}

[1] Aqeel TT, Shabbir AA, Basharat HH, et al. Prevalence of SelfMedication among Urban and Rural Population of Islamabad, Pakistan. Tropical Journal Of Pharmaceutical Research. 2014; 13(4): 627-633. http://dx.doi.org/10.4314/tjpr.v13i4. 22

[2] Eticha T, Mesfin K. Self-Medication Practices in Mekelle, Ethiopia. Plos ONE. 2014; 9(5): 1-5. PMid: 24820769. http://dx.doi .org /10.1371/journal. pone.0097464

[3] Pankaj J, Ajay S, Rajeev KS, et al. Statistical Study on SelfMedication Pattern in Haryana, India. Indo Global Journal of Pharmaceutical Sciences. 2012; 2(1): 21.

[4] Chapman B, Bogle V. Adherence to medication and self-management in stroke patients. British Journal Of Nursing. 2014; 23(3): 158-166. PMid: 24526023. http://dx.doi.org/10.12968/bjon. 2014. 23.3.158

[5] Al-Ramahi R. Patterns and attitudes of self-medication practices and possible role of community pharmacists in Palestine. International Journal Of Clinical Pharmacology And Therapeutics. 2013; 51(7): 562-567. PMid: 23587151. http://dx.doi.org/10.5414/CP2 01814

[6] Belkina T, Al Warafi A, Hussein Eltom E. Antibiotic use and knowledge in the community of Yemen, Saudi Arabia, and Uzbekistan. J Infect DevCtries. 2014; 8(4): 424-429. http://dx.doi.org/10. 3855/jidc. 3866

[7] Koley M, Saha S, Ghosh A, et al. Self-medication tendencies of patients visiting outpatient departments of Government homeopathic medical colleges and hospitals in West Bengal, India. International Journal Of High Dilution Resarch. 2013; 12(45): 178-189.

[8] Khan H, Maheen S, Alamgeer GA, et al. Determinants of Increasing Trend of Self-Medication in a Pakistani Community. Tropical Journal Of Pharmaceutical Research. 2014; 13(3): 437-443. http://dx.doi.org/10.4314/tjpr.v13i3.19

[9] Asyikin A, Agustang AA, Sani Y, et al. Patient and pharmacist interactions in self medication in makassar. International Journal Of Academic Research. 2014; 6(2): 52-56. http://dx.doi.org/10. 7813/2075-4124.2014/6-2/B.8

[10] Hassali M, Shafie A, Al-Qazaz H, et al. Self-medication practices among adult population attending community pharmacies in Malaysia: an exploratory study. International Journal Of Clinical Pharmacy. 2011; 33(5): 794-799. PMid: 21811832. http: //dx.doi.org/10.1007/s11096-011-9539-5

[11] You J, Wong F, Chan F, et al. Public perception on the role of community pharmacists in self-medication and self-care in Hong Kong. BMC Clinical Pharmacology. 2011; 11: 19. http://dx.doi.org /10.1186/1472-6904-11-19
[12] Corrêa da Silva M, Soares M, Muccillo-Baisch A. Self-medication in university students from the city of Rio Grande, Brazil. BMC Public Health. 2012; 12339.

[13] Shehnaz SI, Khan N, Sreedharan J, et al. Self-medication and related health complaints among expatriate high school students in the United Arab Pharmacy Practice (Granada). 2013; 11(4): 211-218.

[14] Klemenc-Ketis Z, Kersnik J. The effect of demographic characteristics on self-medication patterns: a cross-sectional nationwide study from Slovenia. Collegium Antropologicum. 2011; 35(4): 1237-1242. PMid: 22397266.

[15] Alghanim S. Self-medication practice among patients in a public health care system. Eastern Mediterranean Health Journal. 2011; 17(5): 409-416. PMid: 21796954.

[16] Girma BG, Gadisa AD, Kidanemariam ZA, et al. Self-Medication Practices among Health Sciences Students: The Case of Mekelle University, Journal of Applied Pharmaceutical Science. 2011; 1(10): 183-189.

[17] Heidarifar R, Koohbor M, Kazemian Mansourabad M, et al. Selfmedication with Antibiotics among Iranian Population in Qom State Journal of Scientific and Innovative Research. 2013; 2 (4): 785-789.

[18] Selvaraj K, Kumar S, Ramalingam A. Prevalence of self-medication practices and its associated factors in Urban Puducherry, India. Perspectives In Clinical Research. 2014; 5(1): 32-36. PMid: 24551585 http://dx.doi.org/10.4103/2229-3485.124569

[19] Ocan M, Bwanga F, Bbosa GS, et al. Patterns and Predictors of Self-Medication in Northern Uganda. Plos ONE. 2014; 9(3): 1-7. PMid: 24658124. http://dx.doi.org/10.1371/journal.pon e. 0092323

[20] Osemene KP, Lamikanra AA. A Study of the Prevalence of SelfMedication Practice among University Students in Southwestern Nigeria. Tropical Journal Of Pharmaceutical Research. 2012; 11(4): 683-689. http://dx.doi.org/10.4314/tjpr.v11i4.21

[21] Abdo-Rabbo A. Household survey of treatment of malaria in Hajjah, Yemen. East Mediterr Health J. 2003; 9(4): 600-6. PMid: 15748057.

[22] Bianca Anghel I, Crociun C. Self-medication with over-the-counter drugs and antibiotics in romanian consumers: a qualitative study. Cognitie, Creier, Comportament/Cognition, Brain, Behavior. 2013; 27(3): 215-235.

[23] Mohanna M. Self-medication with Antibiotic in Children in Sana'a City, Yemen. Oman Medical Journal. 2010; 25(1): 41-3. PMid: 22125697. http://dx.doi.org/10.5001/omj . 2010.10

[24] Metta E, Haisma H, Kessy F, et al. "We have become doctors for ourselves": motives for malaria self-care among adults in southeastern Tanzania. Malaria Journal. 2014; 13(1): 1-24. PMid: 24986165 http://dx.doi.org/10.1186/1475-2875-13-249 